\title{
ASO Visual Abstract: Surgical Axillary Staging Before Neoadjuvant Chemotherapy: Who Gets It and Why We Should Avoid It
}

\section{Kathleen Iles, MD', Paula D. Strassle, PhD, $\mathrm{MSPH}^{2}$, Chris B. Agala, $\mathrm{PhD}^{\mathbf{1}}$, Julia Button, MD ${ }^{\mathbf{1}}$, and Stephanie Downs-Canner, $\mathrm{MD}^{3}$ (D)}

${ }^{1}$ Department of Surgery, University of North Carolina at Chapel Hill, Chapel Hill, NC; ${ }^{2}$ Division of Intramural Research, National Institute on Minority Health and Health Disparities (NIMHD), National Institutes of Health, Bethesda, MD; ${ }^{3}$ Department of Surgical Oncology, University of North Carolina at Chapel Hill, Chapel Hill, NC

As discussed in our article (https://doi.org/10.1245/s10 434-021-10628-4), despite level 1 evidence supporting post-neoadjuvant chemotherapy axillary staging for nodenegative patients, more than $30 \%$ of women between 2013 and 2017 received pre-neoadjuvant chemotherapy surgical staging. As expected, higher rates of axillary lymph node dissection were observed in this cohort.

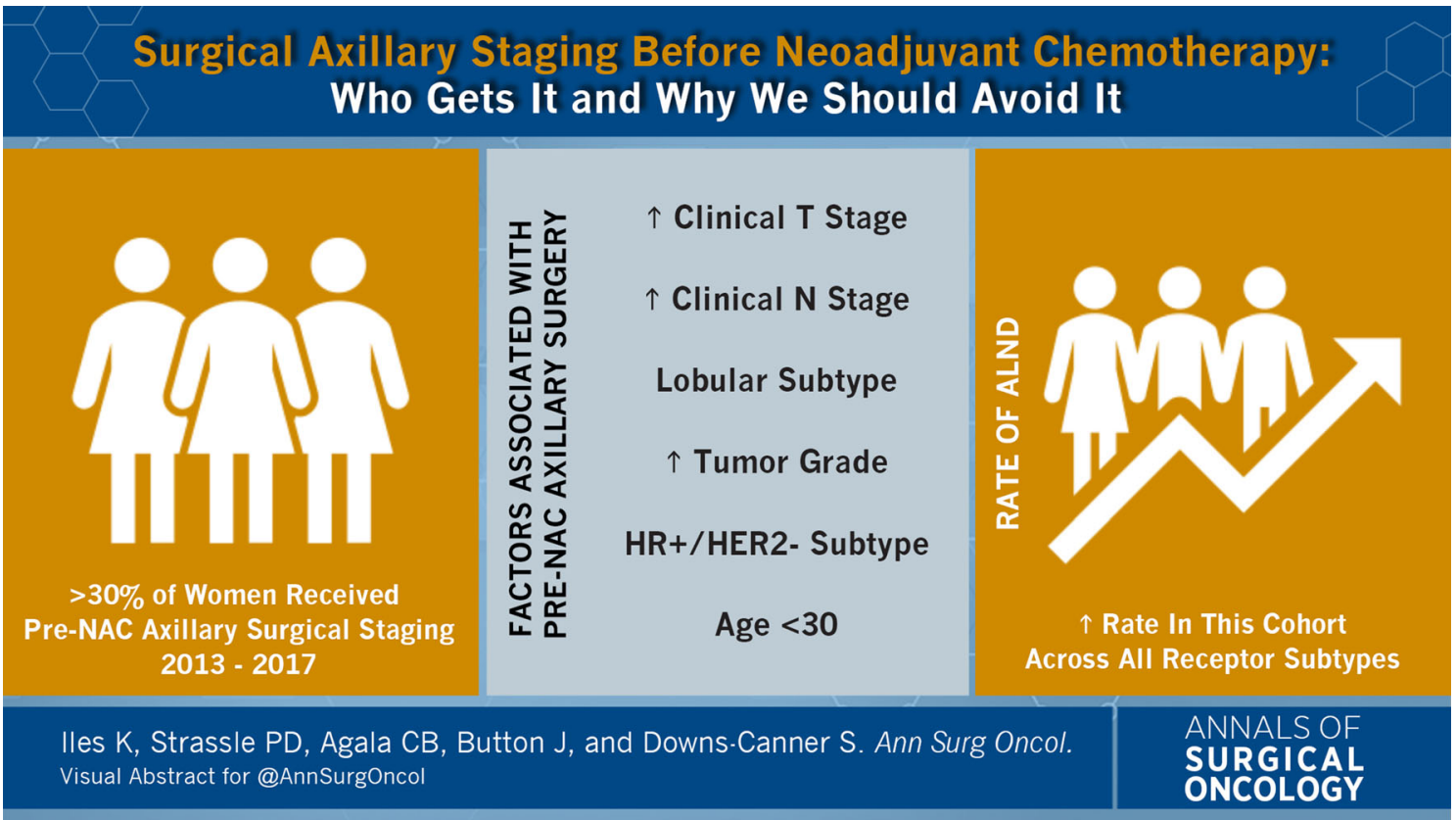

(C) Society of Surgical Oncology 2021

Publisher's Note Springer Nature remains neutral with regard to jurisdictional claims in published maps and institutional affiliations.

Published Online: 21 August 2021

S. Downs-Canner, MD

e-mail: stephanie_downs-canner@med.unc.edu 